\title{
Characterization of Intestinal Collateral Blood Flow in the Developing Piglet
}

\author{
KAREN D. CRISSINGER AND D. NEIL GRANGER \\ Department of Physiology and Biophysics, Louisiana State University Medical Center, \\ Shreveport, Louisiana 71130
}

\begin{abstract}
Interest in the pathogenesis of neonatal necrotizing enterocolitis has prompted study of the intestinal circulation in developing animals. It is conceivable that poorly developed collateral channels may predispose the neonatal intestine to ischemic insults. We therefore characterized intestinal collateral blood flow in anesthetized and ventilated 1-day and 1-month-old piglets. Intestinal blood flow was measured with radioactive microspheres (15 $\mu \mathrm{m}$ diameter) before and after either 1$)$ total occlusion of the superior mesenteric artery (SMA) or 2) occlusion of a distal (jejunoileal) branch of the SMA. After total SMA occlusion in 1-day and 1-month-old piglets, perfusion of the intestine via collaterals from the celiac and inferior mesenteric arteries was not evident. Jejunal, ileal, and colonic (except rectal) blood flows fell to zero $30 \mathrm{~min}$ after ligation of the SMA. Ligation of a distal branch of the SMA in 1-month-old animals significantly reduced total wall (by 25\%) and mucosal/submucosal (by $25 \%$ ) blood flows in the occluded segment. Similar experiments in 1day-old piglets produced significantly greater reduction in total $(70 \%)$ and mucosa/submucosa $(70 \%)$ blood flows. Muscle/serosa blood flows in both groups were not significantly different from control values. In conclusion, collateral perfusion of the intestine via the celiac and inferior mesenteric arteries is insignificant during acute SMA occlusion in the developing piglet. Although there is significant collateral blood flow within the SMA vascular network, perfusion between adjacent gut segments is less effective in preventing intestinal ischemia after occlusion of a branch of the SMA in neonates than in 1-month-old piglets. (Pediatr Res 24: 473-476, 1988)
\end{abstract}

Abbreviations

SMA, superior mesenteric artery

${ }^{46} \mathrm{SC}$, scandium 46

${ }^{85} \mathrm{SR}$, strontium 85

The importance of intestinal collateral blood flow in prevention of intestinal ischemia is well recognized in humans (1-3) and adult animals (4-6). Quantitative studies in adult animals have demonstrated that collateral channels among the major arterial trunks and between adjacent bowel segments both play

Received April 25, 1988; accepted June 14, 1988

Correspondence and reprint requests Karen D. Crissinger, M.D., Department of Physiology and Biophysics, LSU Medical Center, P.O. Box 33932, Shreveport, LA 71130-3932.

Supported by Grant HL-26441 from the National Institutes of Health. K.D.C. was supported by a National Research Service Award Fellowship (DK-08056) from the National Institutes of Health. a role in prevention of intestinal ischemia. In the adult cat perfusion through collateral vessels after occlusion of the superior mesenteric artery maintains flow to the small intestine and proximal colon to within $30-65 \%$ of preocclusion flow (4). However, the efficiency of collateral perfusion via the celiac and inferior mesenteric arteries is substantially lower in dogs after SMA occlusion (5). In adjacent segments of canine small bowel, collateral vessels maintain blood flow in one segment at approximately $55 \%$ of its control level when the artery to that segment is totally occluded (6).

Interest in the pathogenesis of neonatal necrotizing enterocolitis in premature infants has prompted study of the intestinal circulation in developing animals. Although intestinal collateral blood flow has been extensively studied in adult animals, there are no anatomical descriptions or quantitative studies of the collateral circulation in the neonatal intestine. If intestinal ischemia is a major factor in the pathogenesis of necrotizing enterocolitis, then it is conceivable that poorly developed collateral channels may predispose the neonatal intestine to ischemic insults. As the piglet is a popular animal model used to study the neonatal intestinal circulation, the aim of our study was to quantitate intestinal collateral blood flow in the developing piglet.

\section{MATERIALS AND METHODS}

Twenty Hampshire/Yorkshire piglets of either sex were divided equally between 1 -day-old (weight $=1.7 \pm 0.08 \mathrm{~kg}$ ) and 1 month-old (weight $=5.6 \pm 0.4 \mathrm{~kg}$ ) animals. Ten piglets $(n=5$ for each age group) were studied during total SMA occlusion and 10 during occlusion of a distal branch of the SMA. The 1-dayold piglets were fasted for at least $14 \mathrm{~h}$ and the 1-month-old piglets for at least $24 \mathrm{~h}$. After intramuscular injection of ketamine hydrochloride $(20 \mathrm{mg} / \mathrm{kg})$ and xylazine $(2 \mathrm{mg} / \mathrm{kg})$, the animals were anesthetized with pentobarbital sodium (15 mg/kg IV). Maintenance doses of pentobarbital sodium $(5 \mathrm{mg} / \mathrm{kg})$ were given as necessary during the experiment.

Surgical procedure. A tracheostomy was performed immediately after administration of pentobarbital sodium to facilitate artificial ventilation of the animal (Harvard Apparatus Intermediate Ventilator, South Natick, MA). Polyethylene cannulas were inserted into the left carotid, left femoral, and right femoral arteries. The carotid cannula was carefully advanced into the left ventricle while continuously monitoring pressure. The position of the cannula was verified by the characteristic ventricular pressure waveform. The left femoral cannula was used for withdrawal of the reference blood sample and the right femoral catheter for monitoring mean arterial blood pressure. Arterial and ventricular pressures were recorded on a Grass physiologic recorder (model 7D, Grass Instrument Co., Quincy, MA). A cannula was also inserted into the right jugular vein for admin- 
istration of lactated Ringers solution for hydration and as a route for pentobarbital sodium administration.

The abdomen was opened through a midline incision. The SMA or a distal branch (the same branch in each animal, supplying small intestine immediately proximal to the cecum) of the SMA was isolated from surrounding tissues and a loose ligature of silk placed around the vessel. The intestinal loops remained undisturbed within the abdominal cavity during isolation of these vessels. The abdominal organs were then covered with saline-soaked gauze and plastic wrap to minimize evaporative losses. Thirty minutes were allowed before injection of the first microsphere suspension. Body temperature was maintained at $38^{\circ} \mathrm{C}$ via a heating pad and an infrared heating lamp.

Measurement of blood flow. Blood flow to the small intestine, colon, and kidneys was determined using two different radiolabelled microspheres: ${ }^{46} \mathrm{Sc}$ and ${ }^{85} \mathrm{Sr}$. Each microsphere $(15 \pm 3 \mu \mathrm{m}$ diameter, 3M Company, St. Paul, MN) was suspended in $0.9 \%$ saline containing $0.05 \%$ Tween 80 to prevent aggregation. Before injection, each microsphere suspension was thoroughly mixed with a vortex shaker.

Experimental protocol. After the 30-min stabilization period, a microsphere suspension containing approximately 675,000 microspheres $\left(0.3 \mathrm{ml}, 2.25 \times 10^{6}\right.$ microspheres $\left./ \mathrm{ml}\right)$ in 1-day-old or 1,350,000 microspheres $(0.6 \mathrm{ml})$ in 1-month-old animals, was injected into the left ventricle within $15-20 \mathrm{~s}$. Ten seconds before injection, reference sample withdrawal from the left femoral artery was begun (at a rate of $1.36 \mathrm{ml} / \mathrm{min}$ in 1-day and 2.72 $\mathrm{ml} / \mathrm{min}$ in 1-month-old animals) and continued for a total of 70 s (Harvard Apparatus infusion/withdrawal pump, South Natick, MA). A volume of $6 \%$ dextran 70 (Sigma Chemical Co., St. Louis, MO) equal to the reference sample was reinfused through the carotid cannula during the withdrawal period. Arterial pressure was monitored and remained unchanged during the infusion/withdrawal procedure. After the first microsphere injection, the ligature around the SMA or a distal branch of the SMA was tied. A stabilization period of $30 \mathrm{~min}$ was allowed before injecting the second microsphere suspension.

The animals were killed with an intravenous injection of pentobarbital sodium. The duodenum, jejunum, ileum, colon, and kidneys were removed for determination of organ blood flows. The small intestine was divided into $20-\mathrm{cm}$ segments throughout its length. The colon was divided into cecum, colon, and rectum. Intestinal segments were opened, rinsed in isotonic saline, and patted dry. The middle $8 \mathrm{~cm}$ of each $20-\mathrm{cm}$ segment of small intestine was used to measure total blood flow whereas the remaining $12 \mathrm{~cm}$ was divided into mucosa/submucosa and muscle/serosa fractions via blunt dissection. Only total wall blood flow was measured in the colon. The kidneys were divided into smaller portions for uniform geometry within the counting tubes. Organ and reference blood sample activities of ${ }^{46} \mathrm{Sc}$ and ${ }^{85} \mathrm{Sr}$ were measured in a LKB CompuGamma spectrometer (model 1282, LKB Instruments, Inc., Gaithersburg, MD). The error in measurement of the radioactivity induced by spillover of the two isotopes was corrected using ${ }^{46} \mathrm{Sc}$ and ${ }^{85} \mathrm{Sr}$ microsphere standards.

Calculation of blood flow. Organ blood flow was calculated using the following equation:

$$
\text { Blood flow }(\mathrm{ml} / \mathrm{min})=\frac{\text { organ } \mathrm{cpm} \times \text { blood withdrawal rate }}{\text { reference sample } \mathrm{cpm}}
$$

Organ blood flow was normalized to $\mathrm{ml} \cdot \mathrm{min}^{-1} \cdot 100 \mathrm{~g}^{-1}$ organ weight. In each piglet, the following criteria were used to evaluate the reliability of microsphere injections: 1) absence of changes in mean arterial pressure during microsphere injections and 2) agreement within $10 \%$ of the total cpm for both kidneys.

Data analysis. All values are expressed as mean \pm SEM. Occluded blood flows in each age group were compared using Student's unpaired $t$ test and $p<0.05$ was considered significant.

\section{RESULTS}

Mean arterial blood pressure averaged $53 \pm 2 \mathrm{~mm} \mathrm{Hg}$ in 1day-old animals and $79 \pm 2 \mathrm{~mm} \mathrm{Hg}$ in 1-month-old animals during the control (preocclusion) period. After the SMA or a branch of the SMA was occluded, mean arterial pressure rose and then gradually fell toward the baseline pressure, reaching a steady state pressure of $61 \pm 2$ and $93 \pm 2 \mathrm{~mm} \mathrm{Hg}$ after SMA occlusion and $58 \pm 4$ and $75 \pm 3 \mathrm{~mm} \mathrm{Hg}$ after branch occlusion in 1-day and 1-month-olds animals, respectively.

The number of microspheres in the reference blood samples were approximately 15,000 in 1-day and 20,000 in 1-month-old animals. Each tissue sample (except those after total SMA occlusion in which flow fell to zero) contained at least 400 microspheres. Equality between left and right kidney blood flows during the control and occlusion periods corroborated a homogeneous distribution of the injected microspheres. The percentage difference between right and left kidney blood flows before and after occlusion of the SMA or one of its branches averaged $4.5 \% \pm 0.8$ in 1 -day-old animals and $4.95 \% \pm 0.9$ in 1 -monthold animals.

Figure 1 shows control small intestinal blood flow in 1-day and 1-month-old piglets. Figure $1 A$ illustrates total wall, mucosa/ submucosa, and muscle/serosa flow in 1-day-old animals whereas $B$ shows that for the 1-month-old piglets.

With occlusion of the SMA (Fig. 2), blood flow in the jejunum, ileum, and colon (except rectum) fell to zero in both age groups, whereas duodenal flow fell by $32.3 \% \pm 16.1$ and $21.1 \% \pm 8.0(p$ $=\mathrm{NS})$ and rectal flow fell by $46.6 \% \pm 15.9$ and $8.5 \% \pm 3.1(p$ $<0.05$ ) in 1-day and 1 -month-old animals, respectively.

Figure 3 summarizes the responses of intestinal blood flow to occlusion of a distal (jejunoileal) branch of the SMA in 1-day and 1-month-old animals. The percentage fall in total wall and mucosa/submucosa flows were significantly greater $(p<0.01)$ in 1-day versus 1-month-old animals. The percentage fall in muscle/serosa flow was not significantly different between the two groups after occlusion of a distal branch of the SMA or significantly different from control blood flow values.

An observation made in a separate series of experiments, which may be of interest to other investigators, was that mechanical manipulation of the intestine alters the percentage fall in blood flow in 1-month-old animals. We found that bringing the intestine onto the abdomen to isolate a proximal and distal branch of the SMA (rather than isolating the vessels within the abdomen) elicited an intestinal hyperemia. The combination of a fall in blood flow with occlusion and the waning hyperemia induced by manipulation led to an apparently larger fall in total wall and muscle/serosa blood flow (i.e. less apparent collateral blood flow) in 1-month-old piglets. Mucosa/submucosa flow was unchanged with or without manipulation in the 1-month-old animals. No manipulation-induced hyperemia was evident in the 1-day-old animals.

\section{DISCUSSION}

Intestinal collateral blood flow is important in amelioration of ischemic bowel disease in adult humans. Angiographically demonstrated, asymptomatic, isolated occlusion of the celiac, superior, or inferior mesenteric arteries is a common finding (7). However, ischemic tissue injury after mesenteric arterial occlusion is variable (7-9). For example, the inferior mesenteric artery is frequently ligated during surgery for abdominal aortic aneurysms without subsequent infarction of colon supplied by this vessel $(3,10)$.

Intestinal collateral blood flow may occur via anastomotic connections at several levels of vessel branching, including 1 ) the main arterial trunks (celiac, superior, and inferior mesenteric arteries) $(1,4), 2)$ extramural arterial vessels (arterial arcades, marginal arteries) $(6,11)$, and 3 ) intramural vascular plexuses located within the intestinal wall itself $(1,11)$. 

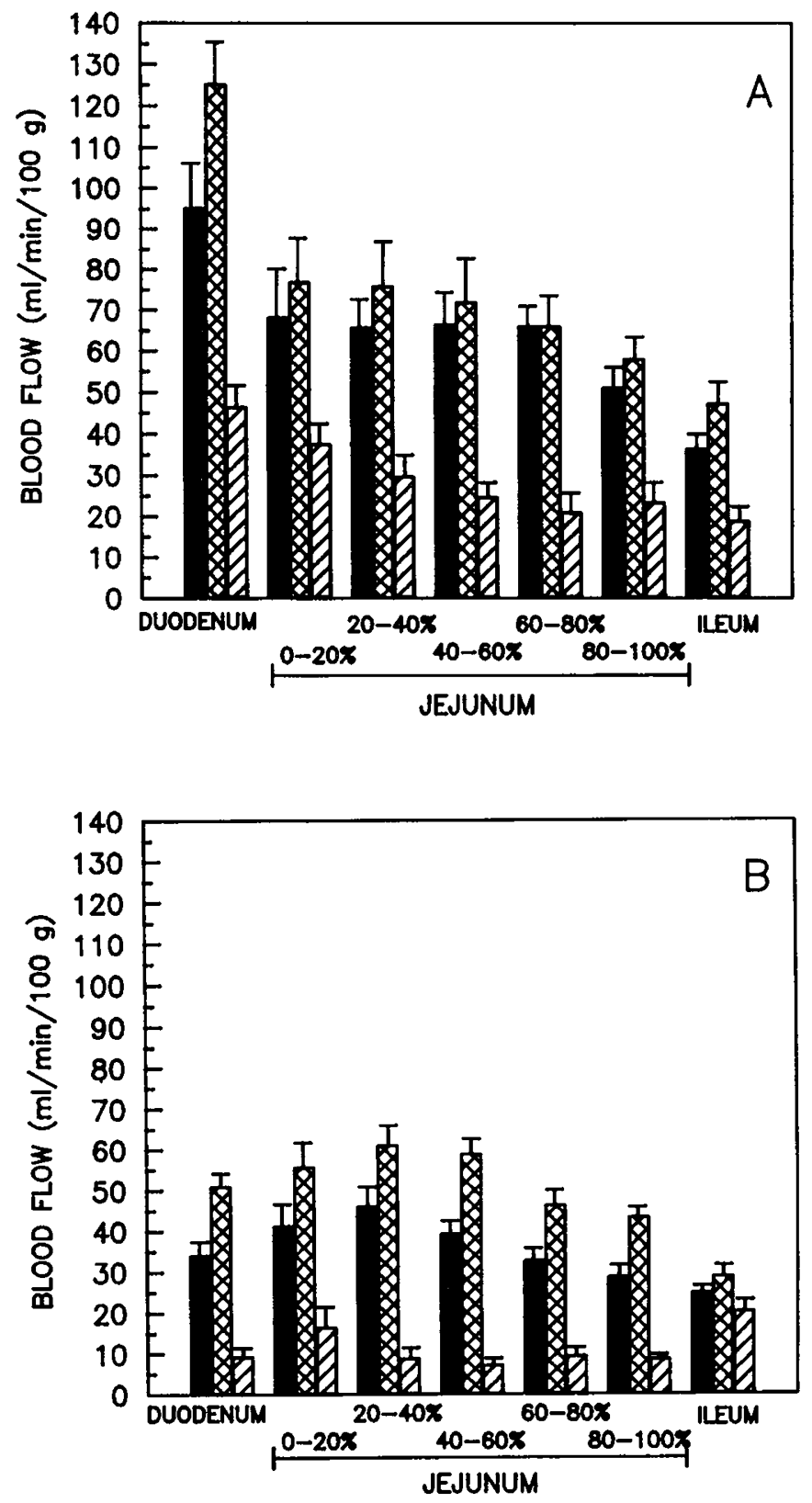

Fig. 1. Control (preocclusion) total (solid bars) and fractionated (mucosa/submucosa, cross-hatched bars; muscle/serosa, diagonal-hatched bars) intestinal blood flow in 1-day $(A)$ and 1-month-old $(B)$ piglets as a function of length along the intestine. Jejunal segments are expressed as a percentage of distance from the ligament of Treitz.

The concept that mesenteric ischemia may play a role in the pathogenesis of neonatal necrotizing enterocolitis in premature infants has stimulated interest in the study of neonatal intestinal blood flow. Characterization of intestinal blood flow and oxygenation in the developing animal, however, has only recently been initiated. The intestine of neonatal piglets appears to be more vulnerable than that of older piglets to reductions in perfusion pressure $(12,13)$ and hemorrhage $(14,15)$ yet it appears to be less susceptible to hypoxic damage induced by acute venous hypertension (16).

In our study, we demonstrated that in the developing piglet collateral perfusion of the intestine via the celiac and inferior mesenteric arteries is insignificant after acute SMA occlusion. This observation is consistent with a previous report on collateral

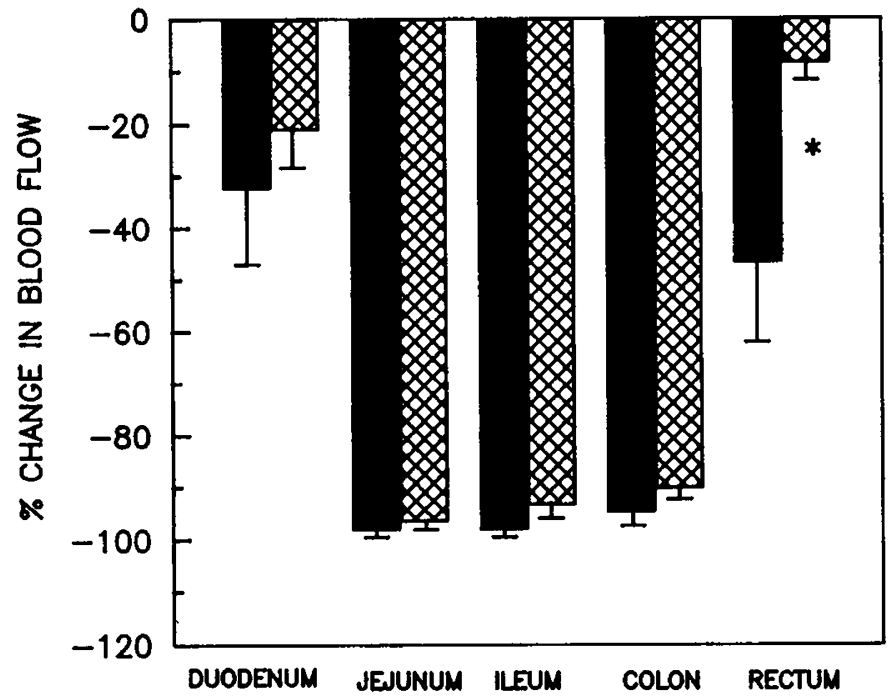

Fig. 2. Percentage change in total intestinal blood flow after occlusion of the SMA in 1-day (solid bars) versus 1-month-old (hatched bars) piglets. An asterisk indicates $p<0.05,1$-day versus 1 -month-old animals.

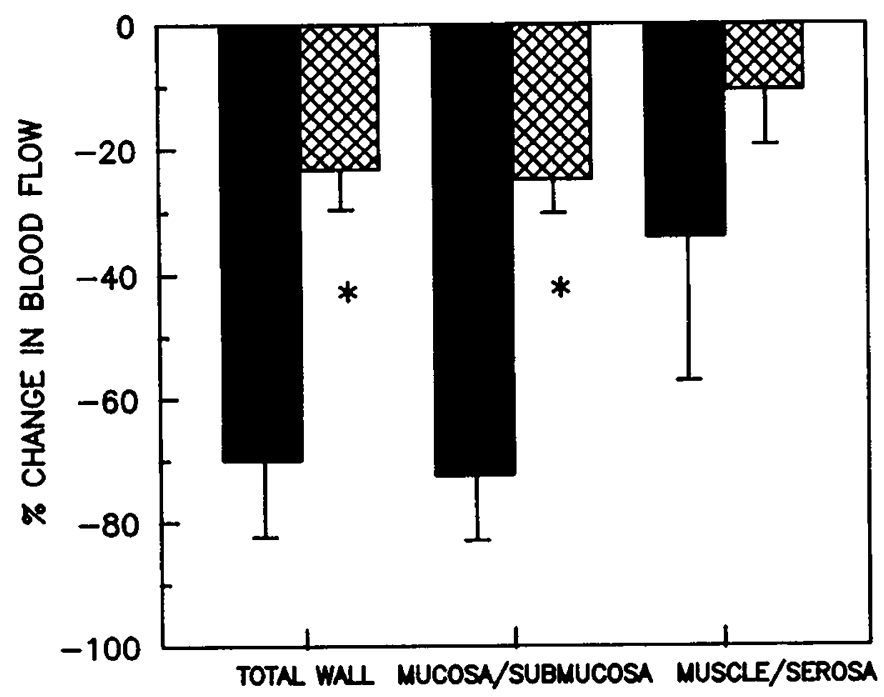

Fig. 3. Percentage change in total and fractionated blood flow to distal jejunoileal segment of small intestine after occlusion of its arterial branch in 1-day (solid bars) versus 1-month-old (hatched bars) piglets. An asterisk indicates $p<0.01,1$-day versus 1 -month-old animals.

blood flow in the intestine of adult dogs (5). However, it is inconsistent with quantitative data from cat intestine (4) and qualitative data from adult humans $(1-3)$. There is no information in the literature regarding intestinal collateral blood flow in human neonates.

Within the SMA vascular network, significant collateral blood flow between adjacent gut segments can be demonstrated after occlusion of a branch of the SMA in both 1-day and 1-monthold piglets. An interesting and potentially important observation in our study was the significantly lower collateral flow between adjacent segments of distal bowel in neonatal piglets. It is unknown if this difference in collateral flow between neonates and 1 -month-old piglets is due to impaired collateral perfusion in existing collaterals (from increased resistance to flow) or an absence of collateral channels.

Evaluation of the intramural distribution of blood flow showed that the reduction in intestinal blood flow observed during occlusion of a distal jejunoileal branch of the SMA is due solely 
to a fall in mucosa/submucosa flow (Fig. 3); flow to the muscle/ serosa is unchanged from control flow. This finding is in agreement with a study recently performed in adult cats after total SMA occlusion (4) in which it was also found that the muscle/ serosa flow is unaffected by occlusion.

In summary, collateral blood flow can be demonstrated within the SMA vascular network of the developing piglet intestine. However, perfusion between adjacent gut segments is less effective in preventing intestinal ischemia after occlusion of a branch of the SMA in neonates than in 1-month-old piglets. This finding suggests that the newborn intestine may be at greater risk from ischemic injury than adult intestine due to poorly developed and/or inefficient collateral blood vessels.

\section{REFERENCES}

1. Michels NA, Siddharth P, Kornblith PL, Parke WW 1968 Routes of collateral circulation of the gastrointestinal tract as ascertained in a dissection of 500 bodies. Int Surg 49:8-28

2. Meyers MA 1976 Griffiths' point: critical anastomosis at the splenic flexure. AJR 126:77-94

3. Saegesser F, Loosli H, Robinson JWL, Roenspies U 1981 Ischemic diseases of the large intestine. Int Surg 66:103-117

4. Premen AJ, Banchs V, Womack WA, Kvietys PR, Granger DN 1987 Importance of collateral circulation in the vascularly occluded feline intestine.
Gastroenterol 92:1215-1219

5. Molstad C, Granger HJ 1981 Collateral circulation in the splanchnic vasculature. Fed Proc 40:491(abstr)

6. Bulkley GB, Womack WA, Downey JM, Kvietys PR, Granger DN 1985 Characterization of segmental collateral blood flow in the small intestine. Am J Physiol 249:G228-G235

7. Novelline RA, Waltman AC, Athanasoulis CA, Baum S 1976 Recent advances in abdominal angiography. Adv Intern Med 21:417-449

8. Kittredge RD 1968 Ischemia of the bowel. Am J Roentgenol Radium Ther Nucl Med 103:400-404

9. Todd TRJ, Weinman G, McIntyre D, Simon JB, Groll A, West RO 1979 Selective superior mesenteric embolization for small intestinal hemorrhage. Can J Surg 22:283-285

10. Ottinger LW 1982 Mesenteric ischemia. N Engl J Med 307:535-537

11. Cho KJ, Schmidt RW, Lenz J 1979 Effects of experimental embolization of superior mesenteric artery branch on the intestine. Invest Radiol 14:207212

12. Buckley NM, Brazeau P, Frasier ID 1986 Intestinal and femoral blood flow autoregulation in developing swine. Biol Neonate 49:229-240

13. Nowicki PT, Miller CE 1988 Autoregulation in the developing postnatal circulation. Am J Physiol 254:G189-G193

14. Buckley BJ, Gootman N, Nagelberg JS, Griswold PG, Gootman PM 1984 Cardiovascular responses to arterial and venous hemorrhage in neonatal swine. Am J Physiol 247:R626-R633

15. Crissinger KD, Granger DN 1988 Developmental changes in intestinal blood flow and oxygen comsumption in response to hemorrhage in the piglet. Gastroenterology 94:A613(abstr)

16. Crissinger $\mathrm{KD}$, Kvietys PR, Granger DN 1988 Developmental intestinal vascular responses to venous pressure elevation. Am J Physiol 254:G658-G663 